\title{
Chitosan Membranes for Pressure Filtration
}

\author{
Osvaldino G. de Brum \\ Departamento de Quimica, Universidade Federal de Mato Grosso do Sul, \\ Campo Grande - MS, Brazil \\ Valdir Soldi, Jair F. Maggioni and Alfredo T. Nunes Pires* \\ Departamento de Quimica, Universidade Federal de Santa Catarina, \\ 88040-900 Florianópolis - SC, Brazil
}

Received: November 11, 1994; May 24, 1995

\begin{abstract}
Utilizando-se membrana assimétrica de quitosana, preparada a partir de uma solução aquosa de ácido acético, foram avaliados o fluxo de solvente e a retenção de diversos macrossolutos. A retenção de solução aquosa de macromoléculas carregadas foi maior do que a de macromoléculas não-carregadas mas com mesma faixa de peso molecular médio. Para evitar a polarização da membrana nos experimentos de filtração, a membrana foi posicionada verticalmente ao campo aplicado.
\end{abstract}

Chitosan membrane was cast by evaporation from an aqueous acetic acid solution and the solvent flow and solute retention were analyzed. The retention of aqueous solution of charged macromolecules was greater than of uncharged macromolecules, but with a similar range of average molecular weight. To avoid membrane polarization in the pressure filtration experiments, the force field acting upon the particles was perpendicular to the flow across the membrane.

Keywords: chitosan membrane, protein, filtration

\section{Introduction}

Chitosan, a deacetylated derivative of chitin, has been used in various applications in the past few years. The polycationic nature of chitosan has been utilized to coagulate wastes in food processing plants ${ }^{1}$, while its chelating properties have been used to detect traces of metals such as $\mathrm{Cd}(\mathrm{II})$ and $\mathrm{Pb}(\mathrm{II})$ in sea water ${ }^{2}$. Chitosan gels have been used in liquid chromatography, and as supports in enzyme immobilization $^{3,4}$. The pervaporation of water-ethanol has been studied using chitosan membranes chemically modified with aldehydes, such as glutaraldehyde and n-butyl aldehyde $^{5}$, chitosan/poly(vinyl alchohol) membranes $^{6}$, and cross-linked chitosan membranes of glutaraldehyde ${ }^{7}$. The application of chitosan membranes for reverse osmosis was studied by Yang and Zall ${ }^{8}$. Ultrafiltration at moderate pressure was used to concentrate solutions with a macrosolute diameter between 10 an $1000 \AA$. This method offers a wide range of uses, such as in juice concentration, purification of waste water, etc $^{9}$. The utilization of chitosan as a raw material is due to the abundance of its precursor. It is obtained from the waste products of the seafood processing industry, with an estimated $1.2 \times 10^{5}$ metric tons of chitin (its precursor) annually available worldwide ${ }^{10}$.

This work was carried out in order to obtain semi-permeable chitosan membranes and to study the solvent flow and the retention of different kinds of macromolecules and protein in a water solution under pressure filtration.

\section{Experimental}

The chitin was isolated from shrimp shells ${ }^{3}$. Due to its poor solubility in a great variety of solvents, a chemical modification of chitin was carried out by basic hydrolysis of the acetamide group, thus obtaining a natural polymer, chitosan, soluble in carboxylic acids. The viscosimetric molecular weight obtained was $(1.55 \pm 0.10) \times 10^{5}$ daltons, 
using the Mark-Houwink parameter equation, where $\mathbf{a}$ and $\mathbf{K}$ are equal to 0.93 and $1.81 \times 10^{-3} \mathrm{~mL} / \mathrm{g}$, respectively ${ }^{11}$. The solvent was aqueous $0.2 \mathrm{M}$ sodium chloride at $25^{\circ} \mathrm{C}$. The degree of deacetylation of $75 \%$ was determined by the Blair method ${ }^{12}$.

Poly(4-methyl vinyl pyridine) [P4MVP] was prepared by the addition of excess methyl bromide to a methanol solution of poly(4-vinyl pyridine), under reflux for $6 \mathrm{~h}$. After the evaporation of the solvent, the P4MVP was crystallized in methanol. Other reagents were supplied by different companies: dextran T2000, dextran T500 and blue dextran from Pharmacia, cytochrome $c$ and ovalbumin from Sigma, and poly(4-sodium styrene sulphonate) from Aldrich. These were used without any additional purification using water as the solvent. Sodium chloride was used to analyze the behavior of macrosolutes in the presence of the ion. The concentrations of blue dextran (MW $2 \times 10^{6}$ daltons) and ovalbumin (MW $4.3 \times 10^{4}$ daltons) solutions were determined by absorbance at 619 and $280 \mathrm{~nm}$, respectively, (Perkin Elmer, Model Lambda 11, UV-Vis spectrometer), and the concentrations of dextran T500 (MW 2.0 x $10^{5}$ daltons) and dextran T2000 (MW $2.0 \times 10^{6}$ daltons) were evaluated by density determination (PAAR DMA 60 densimeter). The concentration of the sucrose solution was determined by means of the refractive index. The flux of the solvent and the retention of macromolecules at a pressure of $200 \mathrm{KPa}$ were determined by using the Millipore filter holders, the pressure being controlled by the regulating valve of a cylinder of compressed air.

A semi-permeable chitosan membrane was obtained by dissolving $3 \mathrm{~g}$ of the chitosan in $80 \mathrm{~mL}$ of dilute acetic acid $[10 \%(\mathrm{v} / \mathrm{v})]$. The resulting solution was spread on a glass plate, or on a sheet of paper and dried at $30^{\circ} \mathrm{C}$ for $6 \mathrm{~h}$. The film thus obtained was soaked with sodium hydroxide [ 1 $\mathrm{M}$ ] for $5 \mathrm{~min}$, and then washed with water for $18 \mathrm{~h}$ to yield the asymmetric membrane.

Scanning electron microscope (SEM, Philips Model $\mathrm{XL} 30$ ) photomicrographs were used to investigate the pore structure and configuration of the chitosan membrane. Figure la shows a cross-section of the chitosan membrane layer. The thickness in this case is about $0.1 \mathrm{~cm}$. Figure $1 \mathrm{~b}$ is a micrograph of the upper surface of the membrane. A typical porous membrane is observed in which the average pore size is about $12.5 \mu \mathrm{m}$ in diameter.

The pressure filtration experiments were performed in a refrigerated centrifuge (Incibras - Spin IV), using dialysis cells made of acrylic plates (Fig. 2). The dialysis cells were assembled so that the membranes were kept moist. The solution was added to one cell compartment and the dialysis cells were placed in the swinging buckets of the centrifuge and spun for $30 \mathrm{~min}$ at different temperatures $\left(4{ }^{\circ} \mathrm{C}\right.$ for proteins and $20^{\circ} \mathrm{C}$ for other macrosolutes). Aliquots of the filtrate were periodically withdrawn and the concentration
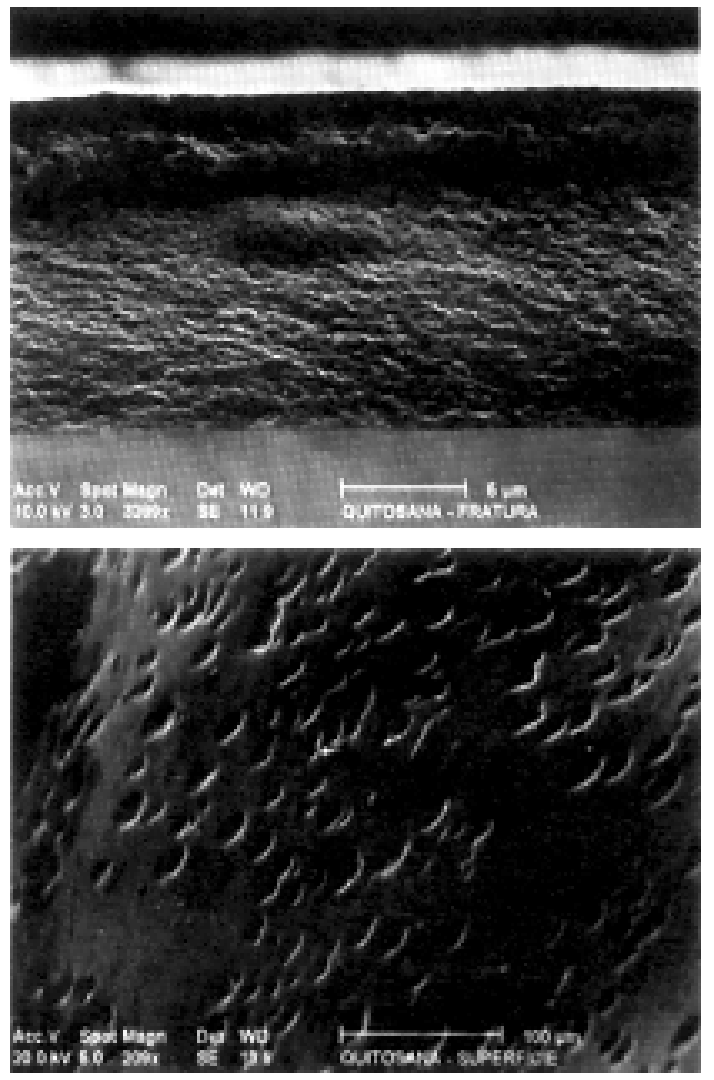

Figure 1. Scanning electron photomicrographs of the asymmetric chitosan membrane. a) Cross-section of the filtration layer. b) Upper surface of a microporous chitosan membrane.

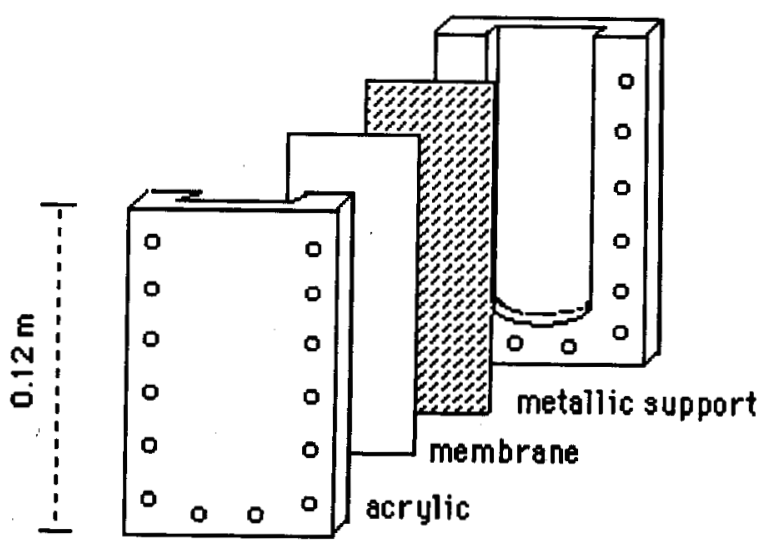

Figure 2. Open view of dialysis cells for ultrafiltration experiments.

of the samples was determined by absorbance or density measurements. To avoid membrane polarization when the pressure was perpendicular, the ultrafiltration system was used with the membrane in a vertical position, parallel to the inertial field of $270 \mathrm{xg}$. Alternatively, the filtration was carried out at a pressure of $200 \mathrm{KPa}$ through the membrane, with an area of $1.36 \times 10^{-3} \mathrm{~m}^{2}$, supported by a Millipore filtration system. 


\section{Results and Discussion}

Figure 3 shows the variation of the solvent flow across the membrane at room temperature, using Millipore filter holders. The solvent flow decreases with time as the membrane becomes more compact, attaining a constant value after $400 \mathrm{~h}$. A comparison of this constant flow value with corresponding flow values of symmetric chitosan membranes ${ }^{13}$ reveals that our system is about 100 times more permeable than the symmetric films.

Table 1 shows the retention of the macrosolute, which is defined as the ratio of the retained mass to the total mass of solute. To obtain the retention of different macrosolutes by the chitosan membrane, we used two different flow systems. In system A, the force field acting upon the particles is parallel to the flow across the membrane, and in system $B$, it is perpendicular to the flow across the membrane. An analysis of Table 1 shows that the retention values of all of the macrosolutes are essentially the same for the two systems (A and B). However, retention varies with the molecular weight and the chemical nature of the macrosolute. Even macrosolutes with the same molecular

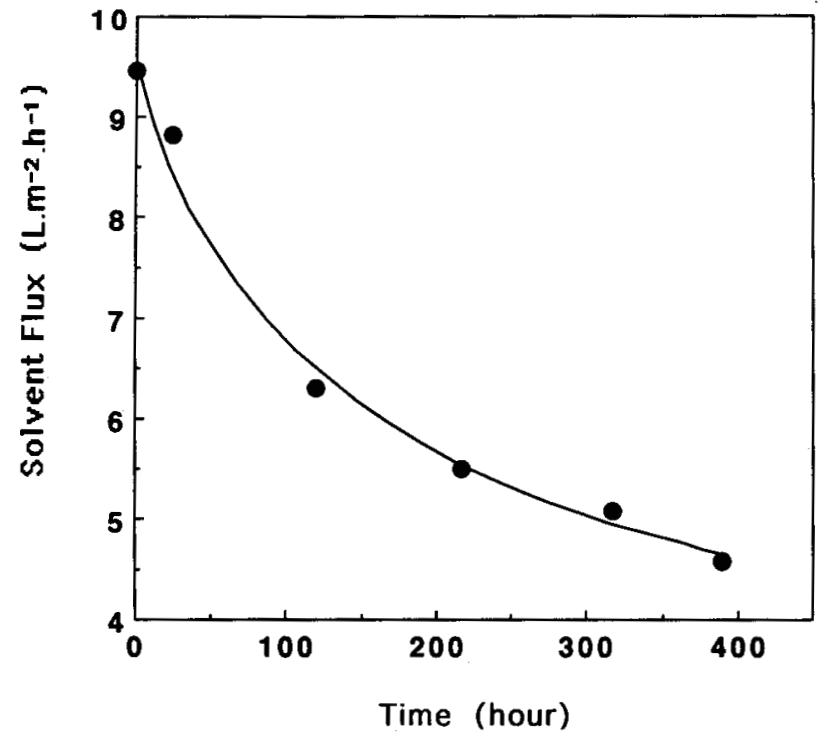

Figure 3. Solvent flow versus time for chitosan membranes at $2 \mathrm{~atm}$ of pressure (system A experiment).

Table 1. Retention of different macrosolutes.

\begin{tabular}{lcc}
\hline \multirow{2}{*}{ Macrosolute } & \multicolumn{2}{c}{ Retention (\%) } \\
\cline { 2 - 3 } & System A & System B \\
\hline P4VMP $(1 \% \mathrm{~m} / \mathrm{v})$ & 65 & - \\
Blue dextran $(1 \% \mathrm{~m} / \mathrm{v})$ & 98 & 100 \\
Dextran T2000 $(1 \% \mathrm{~m} / \mathrm{v})$ & 80 & 86 \\
Dextran T500 $(1 \% \mathrm{~m} / \mathrm{v})$ & 60 & 65 \\
Sucrose & 9 & 9 \\
\hline
\end{tabular}

weight (e.g., blue dextran and dextran T2000) exhibit different retention values, an effect which may be explained by their different total charges. It seems that the different degrees of interaction between the positively charged membrane and the negatively charged macrosolutes are responsible for the observed retention values. In the case of P4VMP, where the macrosolute and the membrane have the same charge, this phenomenon is not observed, and the retention is lower than that of dextran T2000. Therefore, membrane selectivity is due not only to the size of the macrosolute, but also to interactions between the macromolecule and the membrane.

Figure 4 shows the retention effect of poly(4-sodium styrene sulfonate) and blue dextran at different concentrations of sodium chloride after $30 \mathrm{~min}$ of centrifugation. As expected, with an increase in the salt concentration, a retention decrease may reflect a decrease in the electrostatic attractions between the anionic macromolecule and the cationic charges on the membrane surface. Baba et al. ${ }^{14}$ studied the absorption of dyes and ovalbumin on $\mathrm{N}$ propionyl chitosan membranes, and showed the dependence on the electrostatic interaction between an adsorbate and a membrane. Blue dextran, a polysaccharide with a high molecular weight, and the macrosolutes, which can change charge density with a change in $\mathrm{pH}$, such as cytochrome c (a peptide chain with 104 amino acid residues), ovalbumin and hemoglobin (from fish blood), were analyzed. Figure 5 shows the retention of these macrosolutes at different $\mathrm{pH}$ values. The retention of cytochrome $\mathrm{c}$ increases considerably with the increase in the $\mathrm{pH}$, due to the ionic interactions in the solution, which may change their structure and charge. However, in a water solution in the absence of chloride acid or sodium hydroxide to control the $\mathrm{pH}$, the retention of cytochrome $\mathrm{c}$ reaches $93 \%$, due to

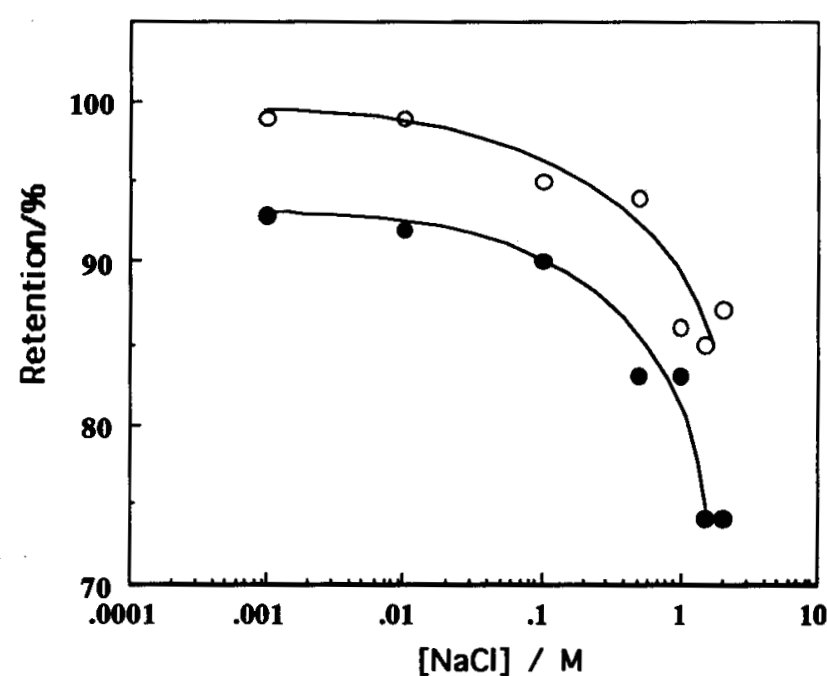

Figure 4, Retention of (o) poly(4-sodiun styrene sulfonate) and $(\bullet$ ) blue dextran $v s$. $\mathrm{NaCl}$ concentration, in system $\mathrm{B}$ experiments. The force field acting upon the particles is perpendicular to the flow across the membrane. 


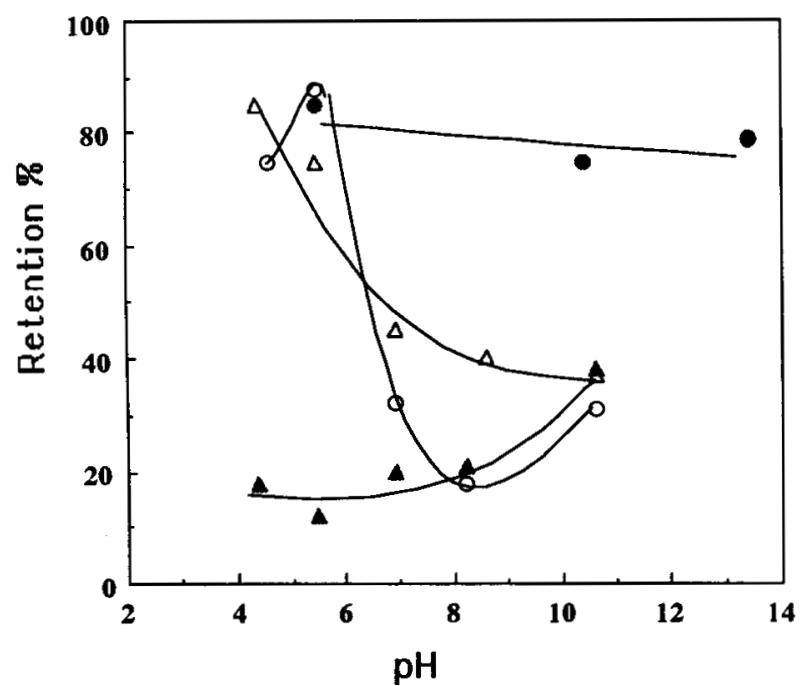

Figure 5. Retention of $(O)$ ovalbumin, $(\Delta)$ hemoglobin, ( $\Delta)$ cytochrome $c$ and $(\bullet)$ blue dextran in experiments with the force field acting perpendicular to the flux across the membrane (system $\mathrm{B}$ ) versus $\mathrm{pH}$ values.

lower hydrogen bonding between the peptide chain and a favorable negative density region interacting with the membrane charge of chitosan. The reduction of the retention for blue dextran with $\mathrm{pH}$ is small because the molecular weight of blue dextran is larger (between 50 and 150 fold) than the studied protein. It is important to mention that at $\mathrm{pH} 10.6$, protein retention is highly uniform, due to membrane charge neutralization. In order to observe the effect of membrane neutralization, one compartment of the dialysis cell was charged with $14 \mathrm{~mL}$ of sodium hydroxide 0.099 $\mathrm{M}$, and after $20 \mathrm{~min}, 6 \mathrm{~mL}$ of the permeate was removed and titrated with $0.10 \mathrm{M}$ aqueous $\mathrm{HCl}$. The final concentration of sodium hydroxide was $0.086 \mathrm{M}$. After successive washings the membrane recovered its original characteristics. For example, when blue dextran was submitted to an ultrafiltration after treatment with a solution of sodium hydroxide $2.0 \mathrm{M}$, the retention was $\mathrm{ca} .37 \%$. After washing the membrane with water or an acidic solution, the retention was $100 \%$.

Positioning of the membrane perpendicular to the flow can be used to concentrate the macrosolute through an osmocentrifugation experiment ${ }^{14,15}$. This experiment uses the same design of the dialysis cell, but the solution is added to one cell compartment and the solvent to the other, up to the same level. At the shortest centrifugation time [3000 $\mathrm{rpm}$ ] a steep concentration gradient of blue dextran or gammaglobulin is obtained, and the concentration in the bottom compartment is 18 times higher than that in the top compartment. After $30 \mathrm{~h}$ of spinning $\mathrm{ca} .94 \%$ of the macrosolute is in the bottom compartment. This preliminary result can extend the application of chitosan membrane to concentrate protein or polyelectrolyte solution by using a different membrane separation method.

In conclusion, the preparation of asymmetric chitosan membranes proved to be easy and reliable. With asymmetric membranes it will be possible to separate proteins with different isoelectric points or polyelectrolytes with different charges. The experimental results show that a macromolecular solution can be effectively concentrated by low-speed centrifugation, provided this is done using dialysis cells fitted with chitosan membranes, and the membrane polarization can be minimized, reducing the filtration time required.

\section{Acknowledgments}

Financial support received from $\mathrm{CNPq}$ and FUNCITEC (Brazil) is gratefully acknowledged.

\section{References}

1. W.A. Bough, Poultry Sci. 54, 1904 (1975).

2. M. Gonzalez-Davila, J.M. Santana-Casiano and F.J. Millero, J. Colloid. Interface Sci. 137(1), 102 (1990).

3.R.A.A. Muzarelli, Chitin (Pergamon, Oxford, 1977).

4. T. Uragami, F. Yoshida and M. Sugihara, J. Appl. Polym. Sci. 28, 1361 (1983).

5. T.Uragami, T. Matsuda, H. Okuno and T. Miyata, $J$. Memb. Sci. 88 (2-3), 243 (1994).

6. Y.M. Lee, S.Y. Nam and J.H. Kim, Polymer Bulletin 29, 423 (1992).

7. M. Goto, A. Shiosaki and T. Hirose. Separation Science and Technology, 29 (14), 1915 (1994).

8. T. Yang and R.R. Zall, J. Food Sci. 49, 91 (1984).

9. H.K. Lonsdale, J. Memb. Sci 9, 121 (1981).

10. D. Knorr, Food Technology 45:1, 114 (1991).

11. G.A.F. Roberts and J. G. Domszy, Int. J. Biol. Macromol. 4, 374 (1982).

12. H.S. Blair, J. Guthrie, T.K. Law and P. Turkington, $J$. Appl. Polym. Sci 33, 641 (1987).

13. R.A.A. Muzzarelli, A. Isolati and A. Ferrero, Ion Exch. Memb. 1, 193 (1974).

14. T. Baba, M. Beppu and C. Kamizawa, Kobunshi Ronbunshu 51(8), 523 (1994)

15. S.P. Nunes, A.T.N. Pires and F. Galembeck, Chemica Scripta 23, 233 (1984).

16. F. Galembeck and A.T.N. Pires, Separation Purification Meth. 15(2), 97 (1986). 